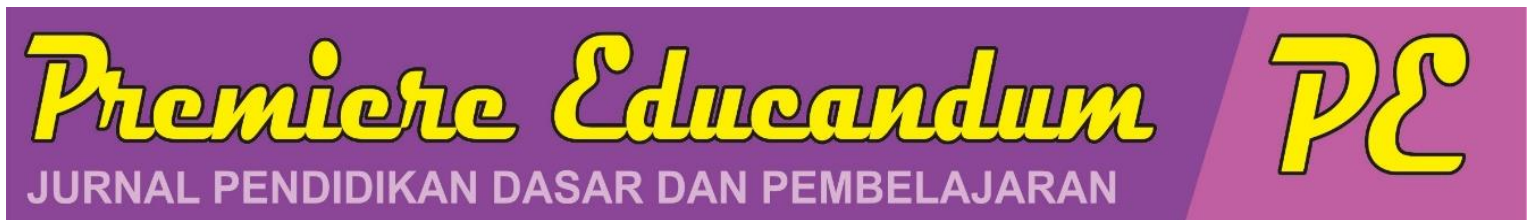

Premiere Educandum: Jurnal Pendidikan Dasar dan Pembelajaran

Volume 8 (2) 185 - 195 Desember 2018

Copyright @2018 Universitas PGRI Madiun

ISSN: 2088-5350 (Print) / ISSN: 2528-5173 (Online)

Available at: http://e-journal.unipma.ac.id/index.php/PE

Doi: $10.25273 /$ pe.v8i2.3282

\title{
Pembelajaran terpadu tipe webbed berbasis budaya lokal untuk meningkatkan hasil belajar siswa kelas IV sekolah dasar
}

\author{
Ali Armadi ${ }^{1}$ \& Yeni Puji Astuti ${ }^{2}$ \\ 1,2STKIP PGRI Sumenep \\ ${ }^{1}$ email: aliarmadi@stkippgrisumenep.ac.id \\ ${ }^{2}$ email: yenipuji@stkippgrisumenep.ac.id
}

\begin{abstract}
The purpose of this research was to analyze and describe the learning problems. Besides, this research was to analyze the learning devices application of webbed type based on local culture that has been known by students' activity, study report, and students' response. This research used Four D models. They are define, design, develop, disseminate. Besides, this research used sequential exploratory. The subject of this research was fourth class. The students' total were 50 students that have divided two class. They were A fourth grade and B fourth grade. The instrument of research used interview, observation sheet, and questionnaire. Further, the limited test result showed that the result was 87.4 and $100 \%$. Meanwhile, the extensive test result showed that the results was 83.1 and $92 \%$. The result questionnaire showed that almost students agreed that the integrated learning of webbed type based on local cultures were easy to follow. Beside, the equipment has supported by the teacher learning that using BAS and LKS. So the students were very interesting. In learning process at SDN Pangarangan III run well, although there were problems when they taught in the class like the pictures as learning media were strength or unfamiliar, the students did not have good motivation when they studied in group, and the students did not know the activity of economic in sumenep clearly.
\end{abstract}

Keywords: Development, Learning Equipment, Integrated Learning, Local Culture, Study Result

\begin{abstract}
Abstrak
Tujuan dari penelitian ini adalah untuk menganalisis dan mendeskripsikan kendala-kendala serta keefektifan dalam penerapan perangkat pembelajaran terpadu tipe webbed berbasis budaya lokal yang dapat diketahui dari aktivitas siswa, hasil belajar dan respon siswa. Penelitian ini menggunakan model pengembangan 4-D (Four D Models) yang dikembangkan oleh Thiagarajan meliputi empat tahap, yaitu define (pendefinisian), design (perancangan), develop (pengembangan) dan disseminate (penyebaran). Penelitian ini dilaksanakan di SDN Pangarangan III Kabupaten Sumenep. Subjek penelitian adalah siswa kelas IV tahun pelajaran 2017/2018 dengan jumlah 50 siswa yang terdiri dari kelas IVA sebanyak 25 siswa dan kelas IVB sebanyak 25 siswa. Instrumen yang digunakan dalam penelitian ini adalah wawancara, angket, dan Adapun hasil yang diperoleh dari hasil uji coba terbatas pada pembelajaran 1-6 diperoleh rata-rata 87,4 dan $100 \%$ dan pada uji coba luas pada pembelajaran 1-6 diperoleh rata-rata 83.1 dan $92 \%$. Dari angket yang diperoleh, rata-rata siswa juga menyatakan bahwa pembelajaran terpadu tipe webbed berbasis budaya lokal yang telah dilakukan dirasa mudah mengikutinya, karena didukung dari cara guru mengajarnya serta BAS dan LKS sehingga siswa merasa sangat berminat dalam belajar. Dalam proses pembelajaran di SDN Pangarangan III berjalan dengan baik, tetapi adapula hambatan yang terjadi berkaitan dengan gambar yang ditampilkan oleh guru sebagai media pembelajaran kurang familiar, siswa kurang bersemangat dalam berkelompok, siswa tidak mengetahui secara jelas mengenai kegiatan ekonomi di Sumenep.
\end{abstract}

Kata Kunci: Pengembangan, Perangkat Pembelajaran, Pembelajaran Terpadu, Budaya Lokal, Hasil Belajar

Histori artikel : disubmit pada 08 Oktober 2018; direvisi pada 30 Oktober 2018; diterima pada 19 November 2018 


\section{A. PENDAHULUAN}

Memasuki era globalisasi MEA (Masyarakat Ekonomi ASEAN) sekarang ini persaingan antar bangsa semakin ketat, sehingga dibutuhkan generasi bangsa yang tak hanya berkualitas namun juga berdaya saing; khususnya dalam penyediaan SDM (Vivi dkk., 2018). Untuk memperoleh sumber daya manusia yang unggul dapat diwijudkan melalui pendidikan. Upaya peningkatan mutu pendidikan terus dilakukan melalui penyeriaan fasilitas pendidikan, peningkatan kualitas tenaga pendidik, perbaikan kualitas kurikulum dan juga perluasa kesempatan untuk memperoleh pendidikan (Galuh \& Indra, 2017)

Kalangan pendidik dan praktisi pendidikan menyadari bahwa banyak faktor yang mempengaruhi keberhasilan siswa di dalam mengikuti proses belajar mengajar di sekolah. Faktor-faktor yang berpengaruh tersebut adalah faktor internal dan faktor eksternal. Faktor internal berasal dari dalam diri siswa yang meliputi minat maupun motivasi dan faktor eksternal berasal dari luar siswa yang meliputi sumber belajar, lingkungan belajar, dan keberadaan media pembelajaran; khususnya pengggunaan teknologi. Menurut Arief dalam Kukuh dan Sutrisno (2017), di dunia pendidikan, khususnya di sekolah-sekolah, perkembangan tekonologi ini ditandai dengan semakin tersedianya fasilitas pembelajaran berbasis teknologi seperti komputer atau laptop.

Berdasarkan hasil observasi dan wawancara di SDN Pangarangan III Kabupaten Sumenep yang telah dilakukan pada Rabu, 7 Februari 2017 peneliti menemukan beberapa masalah bahwa keadaan kelas IV yang umum, pembelajaran cenderung monoton "metode pembelajaran yang digunakan oleh guru adalah pemebalajaran konvensional yakni ceramah, tanya jawab dan pemberian tugas" (Wardana \& Husen, 2017) dan tidak kontekstual (potensi lingkungan setempat, khususnya budaya lokal tidak dimanfaatkan guru secara optimal) hal ini ditunjukkan bahwa siswa kurang bersemangat dalam menerima pelajaran dan menimbulkan kejenuhan. Sehingga setiap diberikan tes, hasilnya cenderung rendah. Bertolak belakang dengan Krissandi (2018) yang menyatakan bahwa pembelajaran dengan menggunakan media berguna untuk memperjelas pesan, memberi rangsangan yang sama, menimbulkan gairah belajar siswa untuk dapat belajar mandiri.

Analisis pada ujian akhir semester yang dilakukan pada semester I tahun ajaran 2016/2017, siswa yang memperoleh nilai ketuntasan belajar di atas nilai standar 70 kurang dari 50\%. Menurut Titi dan Suwarjo (2016:210), keberhasilan siswa dalam belajar bisa diwujudkan dalam bentuk prestasi dan hasil belajar yang tinggi.

Berdasarkan kenyataan di atas, dalam proses penyesuaian diri dengan stantar-standar ouput atau outcome yang terus mengalami peningkatan (Rapih \& Sutaryadi, 2018) maka perlu dilakukan perbaikan dalam kegiatan pembelajaran agar nilai siswa meningkat. Guru dapat berinovasi untuk mengembangkan atau memaksimalkan penggunaan media 
yang ada di sekolah (Sesanti \& Hasim, 2018), Salah satunya dengan mengembangkan perangkat pembelajaran yang menggunakan model pembelajaran terpadu. Hal ini mengingat apa yang disampaikan Jumanto \& Ema (2018) yang menyebutkan bahwa kualitas pembelajaran yang baik dapat diupayakan dengan berbagai cara diataranya adalah dengan memilih metode pembelajaran yang tepat. Pemilihan metode oleh peserta didik tentunya berpengaruh pada setiap aspek pembelajaran. Sesuai dengan Permen No. 44/2015.

Secara konsepsional pengembangan perangkat pembelajaran diharapkan dapat meningkatkan hasil belajar siswa apabila fokus pada tema budaya yang dikembangkan dengan mengintegrasikan budaya lokal dalam prosesnya. Harapannya adalah melalui pembelajaran yang telah dilakukan, dapat membawa pengaruh yang relatif permanen, baik pada aspek perilaku dan pengetahuan, maupun keterampilan-keterampilan berfikir siswa (Santrock, dalam pricilla, 2014). Pengintegrasian budaya lokal dalam proses pembelajaran memerlukan pendekatan pembelajaran berbasis budaya lokal. Pannen (dalam Suprayekti, 2004) mengemukakan bahwa pembelajaran berbasis budaya merupakan strategi penciptaan lingkungan belajar dan perancangan pengalaman belajar yang mengintegrasikan budaya sebagai bagian dari proses pembelajaran. Pembelajaran ini berlandaskan pandangan konstruktivisme yang mengutamakan penciptaan makna di mana siswa mengkonstruksi pengetahuannya berdasarkan pengalaman awal budaya yang telah dimilikinya.

Pembelajaran terpadu berbasis budaya yang holistik-konstruktivistik, berangkat dari subtema lingkungan tempat tinggalku dan dikembangkan berdasarkan pengalaman awal budaya siswa. Hal ini selaras dengan lokasi penelitian ini dilaksanakan yaitu Sumenep, Madura. Sercara histografi kebudayaan, Madura yang memiliki beberapa kabupaten yang notabene masyarakatnya di setiap daerah memiliki keanekaragaman sosial, budaya dan kebudayaan masingmasing, contohnya masyarakat kabupaten Sumenep yang memiliki kebudayaan yang banyak sekali. Contohnya seperti Kerapan Sape, tari mowang Sangkal, Topeng Marlena, Ludruk, Tandha', Pencak silat Pamor, pencak silat Cimande dan lain-lain (Sama', 2017). Penggalian kearifan lokal sangat penting terhadap pembentukan karakter anak indonesia. Nilai-nilai tersebut diantaranya a) nilai spiritual, b) nilai karakter disiplin dan menghargai, c) nilai etika dan moral, d) nilai peduli sosial, e) nilai cinta damai toleransi dan bersahabat. (M. Ridwan \& Wahdian, 2017).

Pendekatan pembelajaran seperti ini diharapkan dapat memfasilitasi siswa menguasai materi pelajaran sebagai upaya meningkatkan hasil belajarnya, melalui budaya lokal. Menurut M. Ridwan (2017), Sumenep dikenal dengan kota budaya dan madura memiliki berbagai budaya tradisional dan berbagai jenis wisata yang sangat beragam. Adapun budaya lokal yang dimaksud pada penelitian ini mengacu pada budaya di Madura diantaranya. 
Dari uraian di atas, perlu dikembangkan perangkat pembelajaran terpadu tipe webbed berbasis budaya lokal untuk meningkatkan hasil belajar siswa kelas IV Sekolah Dasar. Menurut Prabowo (dalam Anggraeni, 2018) menyatakan dari kesepuluh tipe, ada tiga model yang dipandang layak untuk dikembangkan dan mudah dilaksanakan pada pendidikan formal (pendidikan dasar). Ketiga model ini adalah webbed, connected dan intograted.

\section{B. METODE PENELITIAN}

Prosedur dalam penelitian ini menggunakan model pengembangan 4-D (Four D Models) yang dikembangkan oleh Thiagarajan meliputi empat tahap, yaitu define (pendefinisian), design (perancangan), develop (pengembangan) dan disseminate (penyebaran). Penelitian ini menggunakan pendekatan kombinasi kualitatif-kuantitatif model sequential exploratory. Sementara itu, Penelitian ini dilaksanakan di SDN Pangarangan III Kabupaten Sumenep. Subjek penelitian adalah siswa kelas IV tahun pelajaran 2017/2018 dengan jumlah 50 siswa yang terdiri dari kelas IVA sebanyak 25 siswa dan kelas IVB sebanyak 25 siswa. Sedangkan subjek penelitian ini terdiri dari subjek uji coba terbatas dan uji coba luas.

\section{HASIL DAN PEMBAHASAN}

Adapun Hasil belajar siswa setelah mengikuti kegiatan pembelajaran terpadu tipe webbed berbasis budaya lokal pada subtema lingkungan tempat tinggalku siswa kelas IV Sekolah Dasar:

Tabel. 1. Rekapitulasi Hasil Belajar Siswa pada Pembelajaran 1-6 (Uji Coba Terbatas)

\begin{tabular}{|c|c|c|c|c|c|c|}
\hline \multirow{2}{*}{$\mathrm{NO}$} & \multirow{2}{*}{ NAMA } & \multicolumn{2}{|c|}{$\mathrm{N}$} & \multirow{2}{*}{ PHB } & \multirow{2}{*}{$\mathrm{K}$} & \multirow{2}{*}{ KK } \\
\hline & & N1 & $\mathrm{N} 2$ & & & \\
\hline 1 & ARF & 85,4 & 88,8 & 3,4 & $\mathrm{~T}$ & \multirow{12}{*}{$100 \%$} \\
\hline 2 & AN & 83,3 & 94,4 & 11,1 & $\mathrm{~T}$ & \\
\hline 3 & $\mathrm{DN}$ & 72,9 & 83,3 & 10,4 & $\mathrm{~T}$ & \\
\hline 4 & FZ & 62,5 & 86,1 & 23,6 & $\mathrm{~T}$ & \\
\hline 5 & MK & 64,6 & 88,8 & 24,2 & $\mathrm{~T}$ & \\
\hline 6 & MY & 62,5 & 80,5 & 18 & $\mathrm{~T}$ & \\
\hline 7 & NS & 81,3 & 94,4 & 13,1 & $\mathrm{~T}$ & \\
\hline 8 & NAQ & 89,6 & 91,6 & 2 & $\mathrm{~T}$ & \\
\hline 9 & VS & 81,3 & 86,1 & 4,8 & $\mathrm{~T}$ & \\
\hline \multirow[t]{3}{*}{10} & $\mathrm{FS}$ & 72,9 & 80,5 & 7,6 & $\mathrm{~T}$ & \\
\hline & Jumlah & 756,3 & 874,5 & 118,2 & 10 & \\
\hline & Rata-rata & 75,6 & 87,4 & 11,8 & & \\
\hline
\end{tabular}

Keterangan:

N1 : Nilai ulangan harian

N2 : Nilai hasil lembar penilaian

PHB : Peningkatan hasil belajar

K $\quad:$ Ketuntasan (KKM : $\geq 70)$

KK : Ketuntasan Klasikal
Dari tabel 1 diketahui bahwa secara klasikal nilai yang didapat sudah melampaui KKM yang ditetapkan di SDN Pangarangan III Kabupaten Sumenep, sehingga dapat dikatakan tuntas. Melihat pada tabel 
hasil lembar penilaian, diketahui pula nilai terendah yaitu 80,5 dan nilai tertinggi 94,4. Dengan demikian, ada peningkatan sekitar $87,4 \%$.

Sedangkan tes hasil belajar melalui LP terhadap hasil belajar siswa pada pembelajaran 1-6 uji coba luas dapat disajikan pada Tabel. 2 .

Dari tabel 2 diketahui bahwa secara klasikal nilai yang didapat sudah melampaui KKM yang ditetapkan di SDN Pangarangan III Kabupaten Sumenep, sehingga dapat dikatakan tuntas. Melihat pada tabel hasil lembar penilaian, diketahui pula nilai terendah yaitu 58,3 dan nilai tertinggi 97,2. Dengan demikian, ada peningkatan sekitar $11,1 \%$.

Setelah pembelajaran berakhir siswa diberikan angket berupa angket respon siswa pada Tabel 3.

Tabel. 2. Rekapitulasi Hasil Belajar Siswa pada Pembelajaran 1-6 (Uji Coba Luas)

\begin{tabular}{|c|c|c|c|c|c|c|}
\hline \multirow{2}{*}{ NO } & \multirow{2}{*}{ NAMA } & \multicolumn{2}{|c|}{$\mathrm{N}$} & \multirow{2}{*}{ PHB } & \multirow{2}{*}{$\mathrm{K}$} & \multirow{2}{*}{ KK } \\
\hline & & N1 & $\mathrm{N} 2$ & & & \\
\hline 1 & ANA & 96 & 97,2 & 1,2 & $\mathrm{~T}$ & \multirow{27}{*}{$92 \%$} \\
\hline 2 & ASA & 92 & 94,4 & 2,4 & $\mathrm{~T}$ & \\
\hline 3 & $\mathrm{AR}$ & 88 & 91,6 & 3,6 & $\mathrm{~T}$ & \\
\hline 4 & ADR & 56 & 75 & 19 & $\mathrm{~T}$ & \\
\hline 5 & APF & 92 & 94,4 & 2,4 & $\mathrm{~T}$ & \\
\hline 6 & DNS & 76 & 80,5 & 4,5 & $\mathrm{~T}$ & \\
\hline 7 & DML & 92 & 97,2 & 5,2 & $\mathrm{~T}$ & \\
\hline 8 & DMM & 72 & 80,5 & 8,5 & $\mathrm{~T}$ & \\
\hline 9 & FRA & 80 & 83,3 & 3,3 & $\mathrm{~T}$ & \\
\hline 10 & HAK & 100 & 97,2 & $-2,8$ & $\mathrm{~T}$ & \\
\hline 11 & HT & 56 & 75 & 19 & $\mathrm{~T}$ & \\
\hline 12 & $\mathrm{KF}$ & 40 & 63,8 & 23,8 & TT & \\
\hline 13 & MPAW & 44 & 72,2 & 28,2 & $\mathrm{~T}$ & \\
\hline 14 & MFAA & 32 & 58,3 & 26,3 & TT & \\
\hline 15 & NIDH & 68 & 77,7 & 9,7 & $\mathrm{~T}$ & \\
\hline 16 & SNC & 44 & 72,2 & 28,2 & $\mathrm{~T}$ & \\
\hline 17 & NTFD & 76 & 80,5 & 4,5 & $\mathrm{~T}$ & \\
\hline 18 & RMF & 48 & 72,2 & 24,2 & $\mathrm{~T}$ & \\
\hline 19 & RAPP & 76 & 91,6 & 15,6 & $\mathrm{~T}$ & \\
\hline 20 & SAFK & 88 & 91,6 & 3,6 & $\mathrm{~T}$ & \\
\hline 21 & VRZ & 80 & 88,8 & 8,8 & $\mathrm{~T}$ & \\
\hline 22 & VUJ & 56 & 72,2 & 16,2 & $\mathrm{~T}$ & \\
\hline 23 & $\mathrm{ZS}$ & 88 & 91,6 & 3,6 & $\mathrm{~T}$ & \\
\hline 24 & ZSM & 76 & 88,8 & 12,8 & $\mathrm{~T}$ & \\
\hline 25 & ZR & 84 & 91,6 & 7,6 & $\mathrm{~T}$ & \\
\hline \multicolumn{2}{|c|}{ Jumlah } & 1800 & 2079 & 279,4 & 23 & \\
\hline \multicolumn{2}{|c|}{ Rata-rata } & 72 & 83,1 & 11,1 & & \\
\hline
\end{tabular}

Keterangan:

N1 : Nilai ulangan harian

$\mathrm{N} 2$ : Nilai hasil lembar penilaian

PHB : Peningkatan hasil belajar

K : Ketuntasan (KKM : $\geq 70)$

KK : Ketuntasan Klasikal 
Tabel. 3. Rekapitulasi Respon Siswa pada Pembelajaran 1-6 (Uji Coba Terbatas)

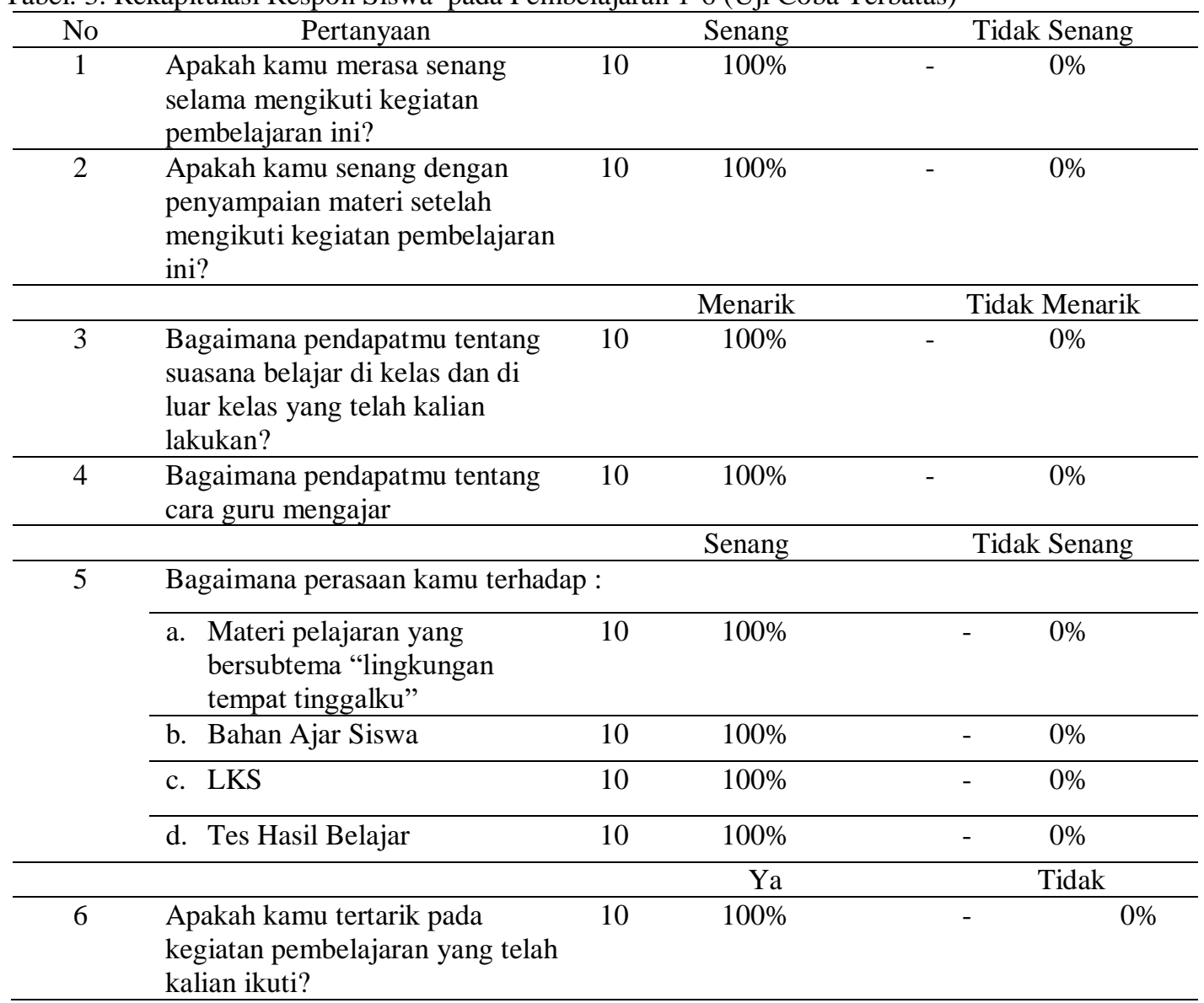

Hasil pengisian angket pada pembelajaran 1-6 uji coba terbatas tentang respon siswa terhadap pembelajaran terpadu tipe webbed berbasis budaya lokal pada Tabel 3 di atas. Diketahui bahwa $100 \%$ siswa senang selama mengikuti kegiatan pembelajaran, $100 \%$ senang dengan penyampaian materi setelah mengikuti kegiatan pembelajaran, $100 \%$ menarik tentang suasana belajar di kelas dan di luar kelas yang telah dilakukan, 100\% siswa senang dengan cara guru mengajar, $100 \%$ siswa mudah memahami yang terkait dengan BAS, LKS, dan LP, $100 \%$ siswa mengaku mudah mengikuti pembelajaran, dan $100 \%$ siswa berminat dalam pembelajaran yang sudah dilakukan. Dari angket yang diperoleh rata-rata siswa juga menyatakan bahwa pembelajaran terpadu tipe webbed berbasis budaya lokal yang telah dilakukan dirasa mudah mengikutinya, karena didukung dari cara guru mengajarnya serta BAS dan LKS sehingga siswa merasa sangat berminat dalam belajar. Sedangkan pada hasil ujicoba luas tentang respon siswa terhadap pembelajaran terpadu tipe webbed berbasis budaya lokal pada Tabel 4.

Selanjutnya, dari hasil uji coba luas adalah bahwa $100 \%$ siswa senang selama mengikuti kegiatan pembelajaran, $100 \%$ senang dengan penyampaian materi setelah mengikuti kegiatan pembelajaran, $100 \%$ menarik tentang suasana belajar di kelas dan di luar kelas yang telah di lakukan, $100 \%$ siswa senang dengan cara guru mengajar, $100 \%$ siswa mudah 
memahami yang terkait dengan BAS, LKS, dan LP, $100 \%$ siswa mengaku mudah mengikuti pembelajaran, dan $100 \%$ siswa berminat dalam pembelajaran yang sudah dilakukan. Dari angket yang diperoleh rata-rata siswa juga menyatakan bahwa pembelajaran terpadu tipe webbed berbasis budaya lokal yang telah dilakukan dirasa mudah mengikutinya, karena didukung dari cara guru mengajarnya serta BAS dan LKS sehingga siswa merasa sangat berminat dalam belajar.

Tabel. 4. Rekapitulasi Respon Siswa pada Pembelajaran 1-6 (Uji Coba Luas)

\begin{tabular}{|c|c|c|c|c|c|}
\hline No & Pertanyaan & \multicolumn{2}{|c|}{ Senang } & \multicolumn{2}{|c|}{ Tidak Senang } \\
\hline 1 & $\begin{array}{l}\text { Apakah kamu merasa senang selama } \\
\text { mengikuti kegiatan pembelajaran ini? }\end{array}$ & 25 & $100 \%$ & - & $0 \%$ \\
\hline \multirow[t]{2}{*}{2} & $\begin{array}{l}\text { Apakah kamu senang dengan penyampaian } \\
\text { materi setelah mengikuti kegiatan } \\
\text { pembelajaran ini? }\end{array}$ & 25 & $100 \%$ & - & $0 \%$ \\
\hline & & \multicolumn{2}{|c|}{ Menarik } & \multicolumn{2}{|c|}{ Tidak Menarik } \\
\hline 3 & $\begin{array}{l}\text { Bagaimana pendapatmu tentang suasana } \\
\text { belajar di kelas dan di luar kelas yang telah } \\
\text { kalian lakukan? }\end{array}$ & 25 & $100 \%$ & - & $0 \%$ \\
\hline \multirow[t]{2}{*}{4} & $\begin{array}{l}\text { Bagaimana pendapatmu tentang cara guru } \\
\text { mengajar }\end{array}$ & 25 & $100 \%$ & - & $0 \%$ \\
\hline & & \multicolumn{2}{|c|}{ Senang } & \multicolumn{2}{|c|}{ Tidak Senang } \\
\hline \multirow[t]{5}{*}{5} & \multicolumn{5}{|l|}{ Bagaimana perasaan kamu terhadap : } \\
\hline & $\begin{array}{l}\text { a. Materi pelajaran yang bersubtema } \\
\text { "lingkungan tempat tinggalku" }\end{array}$ & 25 & $100 \%$ & - & $0 \%$ \\
\hline & b. Bahan Ajar Siswa & 25 & $100 \%$ & - & $0 \%$ \\
\hline & c. LKS & 25 & $100 \%$ & - & $0 \%$ \\
\hline & d. Tes Hasil Belajar & 25 & $100 \%$ & - & $0 \%$ \\
\hline & & \multicolumn{2}{|c|}{ Ya } & \multicolumn{2}{|r|}{ Tidak } \\
\hline 6 & $\begin{array}{l}\text { Apakah kamu tertarik pada kegiatan } \\
\text { pembelajaran yang telah kalian ikuti? }\end{array}$ & 25 & $100 \%$ & - & $0 \%$ \\
\hline
\end{tabular}

Selama kegiatan penelitian berlangsung, peneliti juga mengalami beberapa kendala. Dimana dalam proses pembelajaran di SDN Pangarangan III berjalan dengan baik, tetapi adapula hambatan yang terjadi berkaitan dengan gambar yang ditampilkan oleh guru sebagai media pembelajaran. Banyak dari siswa yang tidak mengetahui maksud dari gambar yang ditampilkan. Seperti contoh : gambar Jokotole. Untuk mengatasi hal tersebut peneliti menyiasatinya dengan mengganti gambar tersebut dengan gambar yang sudah terbiasa siswa lihat di sekolah.
Selama proses pembelajaran berlangsung kebanyakan siswa yang telah dikelompokkan kurang bersemangat untuk melakukan kerjasama kelompok dan mempresentasikannya kepada kelompok lain, dikarenakan stimulasi yang dilakukan oleh guru sangat minim, seperti halnya stimulasi bagi kelompok terbaik mendapatkan hadiah. Hal tersebut tidak lakukan. Peneliti mendiskusikannya dengan guru kelas. Stimulasi apa yang tepat agar tepat dan dapat mendorong siswa lebih bersemangat. Dan peneliti menyediakan reward tersebut. 
Selain itu, dalam proses pembelajaran siswa banyak bertanya tentang tugas yang akan dikerjakan bersama kelompok juga siswa tidak banyak mengetahui tentang kegiatan ekonomi yang ada di Kabupaten Sumenep. Untuk mengatasi kendalakendala tersebut peneliti mendiskusikannya dengan guru kelas. Bahwa siswa membutuhkan penjelasan lebih rinci tentang petunjuk tugas kelompok dan juga mengajak siswa untuk studi lapangan ke pasar yang dekat dengan sekolah untuk melihat kegiatan ekomoni yang ada di Kabbupaten Sumenep.

Pada proses pembelajaran terjadi hambatan pada kegiatan menyanyi dan pemahaman siswa terhadap cerita "Manusia Kerdil". Siswa kurang bersemangat membaca teks nyanyian tanpa musik yang mendukung dan juga banyak dari siswa yang belum mengetahui cerita "Manusia Kerdil". Peneliti mendiskusikan dengan guru kelas untuk mengatasi masalah tersebut, dan akhirnya peneliti mendownload instrumental dan video tentang lagu lir saalir, dan tondu' majang dan juga agar guru memberikan penjelasan terlebih dahulu kepada siswa sebelum siswa mengerjakan kegiatan tugas kelompok.

Pada uji coba luas proses pembelajaran terjadi sedikit pemborosan waktu, dikarenakan kurang memahami isi cerita tentang "Jokotole", sehingga guru harus menjelaskan berulang-ulang. Untuk itu peneliti meminta guru untuk menjelaskan lebih detail pada penjelasan berikutnya. Saat proses pembelajaran berlangsung, siswa banyak yang mengerti terhadap pembelajaran, tetapi ternyata setelah peneliti cek pada lembar penilaian individu, ada satu anak yang belum memahami, bukan memahami masalah pengerjaannya, tapi tidak memahami isi materi. Dalam mengatasi maslah ini peneliti meminta agar guru dan orang tua memberikan perlakuan khusus serta sering diberikan tugas untuk setiap harinya mengenal lingkungan keluarga dan lingkungan sekitar dimana anak tersebut tinggal agar lebih banyak memiliki pengetahuan tentang kebudayaan setempat.

Lebih dari itu, dalam proses pembelajaran terjadi hambatan yang berkaitan dengan gambar yang ditampilkan banyak siswa yang tidak mengetahui gambar yang dimaksud itu apa. Seperti contoh : Keraton Sumenep dan ketika siswa akan diajak untuk studi lapangan ke pasar yang terdekat dengan lokasi sekolah. Hal tersebut membutuhkan pendampingan khusus sebanyak 5 orang dikarenakan siswa yang diajak sebanyak 25 orang. Untuk menyiasatinya peneliti mengganti gambar tersebut dengan gambar yang sesuai dengan bentuk bangunan yang ada pada saat ini dan agar studi lapangan dilakukan di sekolah sebagai penggantinya kantin sekolah digunakan objek dalam kegiatan pembelajaran.

Siswa kurang mengetahui nada dari lirik lagu "Es Lilin Cabbhi", dikarenakan siswa banyak yang tidak mengetahui terhadap lagu tersebut. Selama proses pembelajaran siswa juga kebingungan dalam menentukan peran antagonis dan protagonis pada cerita manusia kerdil. Untuk itu Peneliti meminta agar guru 
menjelaskan pengertian antagonis dan protagonist pada siswa tentang cerita "Manusia Kerdil" dan mengadakan wawancara terhadap guru kelasnya, untuk mendapatkan refrensi, agar perbaikan yang akan dilakukan oleh peneliti dapat membantu siswa mengetahui nada dari lirik lagu tersebut.

\section{SIMPULAN}

Dari hasil uji coba terbatas pada pembelajaran 1-6 diperoleh rata-rata 87, 4 dan $100 \%$ dan pada uji coba luas pada pembelajaran 1-6 diperoleh rata-rata 83.1 dan $92 \%$. Dari angket yang diperoleh, rata-rata siswa juga menyatakan bahwa pembelajaran terpadu tipe webbed berbasis budaya lokal yang telah dilakukan dirasa mudah mengikutinya, karena didukung dari cara guru mengajarnya serta BAS dan LKS sehingga siswa merasa sangat berminat dalam belajar. Dalam proses pembelajaran di SDN Pangarangan III berjalan dengan baik, tetapi adapula hambatan yang terjadi berkaitan dengan gambar yang ditampilkan oleh guru sebagai media pembelajaran kurang familiar, siswa kurang bersemangat dalam berkelompok, siswa tidak mengetahui secara jelas mengenai kegiatan ekonomi di Sumenep.

\section{DAFTAR RUJUKAN}

Anggraeni, A. M. D. (2018). Pengembangan Perangkat Pembelajaran Terpadu Tipe Webbed untuk siswa kelas 1 Sekolah Dasar. Universitas Sanata Dharma. 22 Januari 2018.

Arief, F. (2013). Globalisasi Pendidikan, (online), (http://edukasi.kompasiana.com/ 2011/0608/globaliasasipendidikan-371426), diakses 11 April 2013).

Arikunto, S. (2006). Prosedur Penelitian Suatu Pendekatan Praktik, Jakarta: Balai Pustaka.

Budiyanto. (2005). Pengantar Pendidikan Inklusif Berbasis Budaya Lokal, Jakarta: Depdikbud.

Fogarty, R. (1991). How To Integrated The Curricula, Palatine, Illions:IRI/Skyligth Publishing, Inc.

Hermawan, A. H. (2008). Pembelajaran Terpadu di SD, Jakarta: Universitas Terbuka.

Jumanto \& Ema B. P. (2018). Pengaruh Metode Tutor Sebya Berbasis Video Youtube Terhadap Pengembangan Sikap Kemandirian. Jurnal Profesi Pendidikan Dasar. 5(1), ppd.v1i1.5372.

Krissandi, A.D.S. (2018). Pengembangan Video Tematik Sebagai Pengantar Pembelajaran Kurikulum 2013 di Sekolah Dasar. Premiere Education; Jurnal Pendidikan Dasar dan Pembelajaran. 8(1), 68-77.

Miller, B. A. (2013). Joining Forces: A Collaborative Study of Curricular Integration". International Journal of Education \& the Arts. 14(19), 3.

Niswatuzzzahroh, V. 2018. Penerapan Model Discovery Learning Berbantuan Media Audio Visual untuk meningkatkan Literasi Sains Siswa. Universitas Muria Kudus. 28 Agustus 2018.

Permendikbud, 2013. Tentang Standar Proses Pendidikan Dasar dan 
Menengah Nomor 65 Tahun 2013. Jakarta: Depdikbud.

Peraturan Menteri Pendidikan Dan Kebudayaan Republik Indonesia. 2013. Implementasi Kurikulum Pedoman Umum Pembelajaran Nomor 81a Tahun 2013. Jakarta: Depdikbud.

Purwanto. 2013. Evaluasi dan hasil Belajar. Yogyakarta: Pustaka Belajar.

Rapih, S. \& Sutaryadi. (2018). Perspektif Guru Sekolah Dasar Terhadap Higher Order Yinking Skills (HOTS): Pemahaman, Penerapan, Hambatan. Premiere Education; Jurnal Pendidikan Dasar dan Pembelajaran. 8(1), 78-87.

Ridwan, M. (2017). Tradisi Nyanyian Anak Terhadap Pembentukan Karkater Anak Usia Sekolah Dasar. Sekolah Dasar; Kajian Teori dan Praktik Pendidikan. 26(1), 49-61.

Ridwan, M. \& Wahidin, A. (2017). Structure, Function and Value The Tradition of Oral Literature in Sumenep Madura. ISSLAC: Jurnal Of Intensive Studies of Linguage, Literature, Art and Culture. 1(1), 252-273.

Sama'. (2017). Kajian Sosiologi dalam Paparegan Madura di Kecamatan Bluto Kabupaten Sumenep, Madura. Kode 751. Sosial Humaniora, Seni Budaya dan Pendidikan.

Sesanti, N. R. \& Hasim R. S. A. 2018. Media Puzzel Sogam (Soal dan Gambar) Pada Materi Penjumlahan dan Pengurangan Bilangan. Jurnal Bidang Pendidikan Dasar (JBPD), 2(2).

Suprayekti. (2004). Pembaharuan Pembelajaran di SD, Jakarta: Pusat Penerbitan UT.
Sugiyono. (2013). Metode Penelitian Kombinasi (Mixed Methods), Bandung: Alfabeta.

Sumarno, Alim. (2011). Pengertian Hasil Belajar, (http://elearning.unesa.ac.id/tag/t eori-hasil-belajar-gagne-dandriscoll-dalam-buku-apa).

Suryansyah, T. \& Suwajo. (2016). Pengembangan Video Pembejaran Untuk Meningkatkan Motivasi dan Hasil Belajar Kognetif. Jurnal Prima Edukasi, 4(2). Yogyakarta.

Suwarjo \& Pricilla A. (2014). Pengaruh Problem Based Learning Terhadap Keterampilan Berfikir Kritis dan Regulasi Diri Siswa. Jurnal Prima Edukasi, Universitas Negeri Yogyakarta. 2(2).

Thiagarajan, S. Semmel, Dorothy S, Semmel, \& Melvyn I. (1997). Imtructional Devlepment for Training Teachers of Exeptional Children, Minesota: The Council for Exeptional Children.

Trianto. (2007). Model-Model Pembelajaran Inovatif Berorientasi Kontruktivistik, Jakarta : Prestasi Pustaka.

Usman, Moh. U. (1997). Menjadi Guru Profesional, Bandung: PT Remaja Rosda Karya.

Wardana, L. A. \& Husen C. (2017). Implementasi Pendekatan Saintifik Untuk Meningkatkan Prestasi Belajar Siswa pada Mata Peajaran IPS. Jurnal Pendidikan Dasar Nusantara. 3(1).

Winarsunu, T. (2009). Statistik dalam Penelitian Psikologi dan Pendidikan, Malang: Universitas Muhammadiyah Malang. 
Widiana, G. T. \& Wardani I. K. (2017). Efektifitas Suplemen Bahan Ajar IPA dengan Pendekatan Saintifik Untuk
Siswa Kelas IV SD. Jurnal Pendidikan Dasar Nusantara. 3(1). 